\title{
EVOLUTIONARY PRE-ADAPTATION AND THE IDEA OF CHARACTER IN FICTION
}

\author{
Keith OATLEY and RAYMOND A. MAR \\ Department of Psychology, University of Toronto
}

\begin{abstract}
Fiction can be a means of striving towards truths, but in a way that is more abstract than the truths of everyday happenings. We offer a staircase of evolutionary pre-adaptations on which works of literature such as novels and plays depend. These include systems of mirror-neurons, mimetic ritual, conversational language based on actions, narrative structure, metaphor, and imaginary play. These enable the mental simulations that people create when they listen to, or read, stories. We argue that the abstraction of literary character is a sophisticated version of the making of mental models of others that we form routinely in conversation.
\end{abstract}

Keywords: fiction, pre-adaptation, simulation character

\section{ART, LITERATURE AND USEFULNESS}

Art involves the creation of objects that are external to the mind, that persist through time, and that can often travel beyond the site of their original creation (OATLEY 2003). Whereas there is not much of an evolutionary puzzle about how objects such as a stone tool or a computer might acquire adaptive value, objects of art do seem puzzling. They do not seem directly useful. In this paper, we argue that a case for the functional purpose of art can be made. We offer such a case for one form of art: narrative fiction.

The words "poetry" and "fiction" both mean something made and, worse still for any evolutionary argument, fiction is often thought of as a synonym for falsity (cf. LAMARCQUE 2003). There seems to be a problem with any aesthetic proclivity humans might have towards fiction, in that for evolutionary purposes adaptations to the true should be better than adaptations to the false. TOOBY and CosmiDEs (2001) offer two kinds of answer to this problem. One is that the means by which evolutionarily derived genes direct activity is by installing species-typical action patterns and preferences, which together with learning, then form the bases of goals for certain kinds of food, sex, safety, and so on. These preferences are the bases for aesthetic pleasure. The second is that because the human cognitive system is too complex to be controlled by 30,000 genes, it needs to be responsive to local con- 
ditions and contingencies. Fiction allows the system to be, as TOOBY and Cosmides say, "calibrated".

Here we offer an idea that is related but different, based on OATLEY's (1992a) idea of fiction as a kind of simulation. The idea derives from ARISTOTLE's concept of mimesis (ARISTOTLE, trans. 1970; HALLIWELl 2002). Whereas TOOBY and CosMidES accept that fiction is false and set about to solve the puzzle that this poses, we propose that fiction can be true, but at a different conceptual level than that of the everyday. This level involves both abstraction and detail. Think of it like this. A watch or clock is a simulation of celestial motions. It is useful because it allows us human beings to coordinate our activities, even when we cannot directly see the sun or stars. Indeed, it allows a more precise coordination of such activities than if one were to say "I'll meet you here when the pole star is thirty degrees above the horizon". And what if the night is cloudy? A clock does not depend on direct celestial observation. One might even say that the model that it embodies is false; in older clocks at least it poses a fixed earth-like center with the sun revolving round it. Even modern clocks have a tendency to falsity, because any read-out of time is but an estimate. Despite this, one is not tempted to make arguments for the falsity of what is represented because when one thinks about a clock one knows it is not itself the movement of celestial bodies. It is a model. Models are approximations with necessary simplifications that yield useful predictions of complex environments. Similarly, fiction is not life. Any of its parts may have no necessary empirical correspondence to the world, nonetheless it is a model, a useful simulation, of selves in the social world.

Human beings evolved to embody circadian clocks (models) that more or less control sleeping and waking. We propose humans also evolved to make models of aspects of the social world, and that literary art is an extension of this ability. Social models have been taken up and molded by culture to provide the contexts for oral storytelling and more recently written literature. These products, as mentioned above, yield new advantages similar to other artistic products, such as permanency and increased frequency and ease of dissemination. The relationship between stories and the social-models they are based upon is complex however, and influence between the two is bi-directional. Social-models aid in the creation of stories, and stories help to advance and shape mental models of the social world. In this article we propose that one distinctive feature of literary fiction, namely character, derives from essential human social abilities, and that the telling of stories and the reading of literature also help to develop these abilities. Fiction is, therefore, useful, and hence of potential adaptive value. 


\section{A DERIVATION OF STORIES FROM HUMAN SOCIALITY}

Human evolutionary adaptation is marked by two salient features: sociality and technology. Technology is dependent on sociality, in that the tool-creation is frequently collaborative and the dissemination of tool-knowledge within a culture is inevitably social. Arguably the most important technology yet developed is writing, itself an extension of social-communication. We propose that because the trajectories of individual selves in society are complex, we have become enabled to understand them more deeply, by means of language and narrative, than, say, chimpanzees can understand their societies.

DunBAR $(1993,1996,2004)$ has offered an evolutionary explanation for the development of language, in which he proposes that language derives from social interaction. He has thus provided a route towards understanding how narrative stories are universals, not confined to specific cultures or local environments. Here we offer an evolutionary sequence towards this conclusion with seven steps, starting with features of primate sociality.

1. Knowledge of individuals. A distinctive attribute of the societies of chimpanzees and bonobos, our nearest non-human relatives, is that all the members know individually all the other members of the group in which they live. Goodall (e.g., 1986) achieved an ethological breakthrough by herself learning to recognize as individuals members of a group of wild-living chimpanzees, who had habituated to her presence. Only with the recognition of individuals could she begin to understand the social organization of this species. Each individual in a primate group is aware of the hierarchical position occupied by the self and others. Each knows who is related to whom, who is a friend, who is a potential antagonist, and who has alliances with whom else. Chimpanzees, thus, appear to have a representation of their social world containing at least a few discrete categories for individual members.

2. Correlation of size of social group with size of brain. The human brain is about $1600 \mathrm{cc}$, compared to about $180 \mathrm{cc}$ for a non-primate mammal of our body weight. A huge increase in the size of the neocortex accounts for most of this difference. In humans the neocortex is about $80 \%$ of the total brain volume. While increased brain size in primates is correlated with fruit eating and foraging over large territories, DUNBAR $(1993,1996)$ argues it is also associated with living in highly interactive social groups. While older theories attributed the enlarged human cortex to increases in manual and mental skills, DUNBAR has proposed a more plausible idea. AIELLO and DUNBAR (1993) observed that the proportion of neocortex relative to the rest of the brain is linearly related to the maximum size of the social group in which each species lives. Compared to chimpanzees whose maximum group size is 50, humans know and interact with three to four times as many individuals (between 150 to 200). 
This suggests that increases in brain size among primates are related to the greater computing power needed to know individually all the members of increasingly large social groups. While this hypothesis has not been without its critics (see DunBar 1993) it has recently become quite widely accepted.

3. Physical mimesis. Donald (1991) argues that an important stage in the evolution of mind, which occurred with the emergence of homo erectus 1.9 million years ago, was of what he calls mimesis: a pre-verbal imitation of the actions of others, a quasi-symbolization. It allowed the communication of skills such as the manufacture of stone tools, and communal activities such as rituals. Aspects continue into modern times, for instance in apprenticeships, in dance, and in the picking up of tunes and songs. In non-human primates, this ability for behavioural imitation and mimicry is served by so-called "mirror neurons", neurons which fire both when an action is personally enacted, and when an identical action is observed (e.g., GaLlese et al. 2002). Similar neurons are also found in humans (e.g., IACOBONI et al. 1999), and it has been proposed that these played a fundamental role in the evolution of language among our early ancestors (RIzZOLATTI and ARBIB 1998). As GaLLESE, KeYSERS and Rizzolatti (2004) point out, what is at issue here is the transition from societies based on immediate cues to societies based on knowledge of other individuals.

4. Emergence of language as conversation: verbal grooming. In primate social groups friendly relationships are maintained by mutual grooming, in which pairs of animals sit quietly together and pick through each other's hair for twigs and parasites. Chimpanzees spend about 20\% of their time in this way. DunBar (e.g., 1996) has calculated that the maximum amount of time a primate could possibly spend on grooming would be $30 \%$, without this time impinging on sleep and foraging. But as group size increases, so does the number of friendly relationships one needs to maintain, and consequently the amount of grooming one must do. As the size of social groups increased in the line that led to modern humans, a crisis occurred: how could relationships be maintained successfully given the limited amount of time in each day? DUNBAR has postulated that the answer was conversation. According to this idea, language did not evolve for such purposes as coordinating hunting, although it is certainly useful in this domain. It emerged as verbal grooming to cultivate and maintain relationships. Manual primate grooming typically occurs with only one other individual at a time, and it excludes other activities. Conversational grooming can be performed in social groups larger than two, and it can be done during activities such as preparing food. DunBAR estimates that conversation began between 500,000 and 250,000 years ago.

More recently, BARRETT, ReNZI and DunBar (2003) have extended DunBaR's hypothesis to include the fact that, as compared with monkeys who live constantly and gregariously in the same troupes, apes and humans live in fission-fusion societies, which separate and rejoin each other. They propose that this kind of society is 
cognitively more demanding than the societies of monkeys. Whereas monkeys can conduct their social interactions on the basis of immediate social cues, members of fission-fusion societies have to maintain relationships out of sight of the individuals with whom they are relating: they have to be able to represent individuals who are not present.

5. Narrative and making sense. Up until this point we have referred to links between language and social processes with little attention to content. The nature of language-based communication, however, also points toward a social basis and purpose. Conversation is of two main kinds. Practical conversation has a goal outside itself: the conversation is essentially a means of agreeing on joint goals, of planning activities to attain them, and in some cases, for example where the goals are informational, to enact the plans (POWER 1979). Companionable conversation has a goal that is essentially the conversation itself, and this is the grooming type of conversation that DUNBAR has described. It is not known, of course, how long after the emergence of conversational language narrative forms arose. TOMASELLO (1999) has examined this question from the perspective of individual child development, focusing on what he has called verb islands. A verb island is a concept similar to FILLMORE's (1968) case grammar, describing a familiar action (walk, throw, drop, etc.) together with a small number of syntactic slots for an agent, an object, an outcome, and so on. TOMASELLO has found that children's earliest constructions beyond two words are based on such verb islands. Here is an example, comment on a recent lapse by the child's father: "Daddy drop the plate." It is not a long reach from there, either for ourselves when young, or for our historical forebears, to narrative forms that depict agents, their intentions, and the outcomes of actions. In studies of what people talk about, DUNBAR (1993) has found that some 60\% of conversation in a university refectory was about the social lives of the conversants and their acquaintances. Companionable conversation is about selves, friends, enemies, the trusted, and the untrustworthy. What is known as gossip, the recitation and analysis of action and character, enables conversants to elaborate models of others with whom they have had dealings in the past and with whom they may have dealings in the future. Companionable conversation is often enacted in a narrative form. As the recitation of goal-oriented behaviour of people we know forms the basis of real-world traitjudgements, historical and fictional stories form around depictions of goal-oriented actions by protagonists who may be alive, or dead, or imaginary.

Making sense of chimpanzee and bonobo society involves narrative accounts of the kind that have been offered by GoODALL (1986), DE WAAL (1982) and other primatologists, even though the animals concerned could not construct such accounts themselves. Humans are even more social than chimpanzees and bonobos. We know even more about the individuals in our social network. Interactions become even more complex. The ability, present in non-human primates is most probably based 
on mirror neurons (discussed above) which as GaLlese, KeYSERS and RizzOLATTI (2004) say: "allow us to directly understand the meaning of the actions and emotions of others by internally replicating ... them without any explicit reflective mediation" (p. 396). This is an important preadaptation for narrative, because as we come describe actions to ourselves and each other in language, and indeed in narrative terms, we can come to know the workings of selves and society more explicitly, and hence more keenly, than could the chimpanzees and bonobos know their societies. Further elaboration occurs in stories told by storytellers, at first not so much fiction as accounts of the social group and salient people in the group. This involves being able to think of the contents of other people's minds which, as MAR (2004) has shown involves distinct neural circuitry that is shared with circuitry that subserves narrative. Gallese, KeYSERS and RizzOlatTi talk of the mirror neuron system in terms of simulation. As DUNBAR (2004) points out, human abilities include those off recursion: we can know what another knows, and know what another knows about what one knows oneself. Such recursion is necessary for conversation and narrative, which involve at least three levels of recursion. A conversationalist or story-teller must know (1) that the hearer can know (2) what a person in the story knows (3). We take simulation together with its recursive aspects to be important steps towards the more explicit simulations of fiction, which requires a further increase of abstraction, to depict people who may never have existed or acted in the ways depicted.

The two recurrent features of all narratives are that there are characters and that stories involve the making of meaning and purposeful progress towards a point: perhaps of social comparison (in gossip), and of implicit social rules. SCHANK and BERMAN (2002) have argued that all stories have didactic (that is to say useful) purposes.

6. Emergence of metaphor and the symbolic. Between about 50,000 and 30,000 years ago, a new development occurred among humans. Our ancestors started burying their dead with more or less elaborate rituals. They started making ornaments, and they started painting. As Mithen $(1996,2001)$ has argued, these activities presuppose a movement from an encapsulated kind of cognitive system - which has also been called the Swiss Army Knife model (Cosmides and Tooby 1994) - in which each mental tool is useful but does not interact with others, to one characterized by more interaction and cross-relation. Thus 60,000 years ago (say) our prehuman ancestors had elaborate knowledge of individuals in their social network (as discussed above) and the corresponding skills for social interaction. They had elaborate knowledge of the natural history of plants and animals that provided their food sources. They had technical skills such as how to make fire, shelters, and stone tools. But each of these knowledge bases was domain specific, largely procedural, and did not interact with others. MitHEN's argument is that around 50,000 years ago, the barriers between the specialized compartments of the mind started to become porous. 
The result was metaphor: a this is a that, a something is something that it is not, sitting close to a friend is as comforting as a particularly satisfying piece of food. Although BARRETT, HENZI and DUNBAR (2003) postulate the beginnings of analogical reasoning with the new cognitive demands of fission-fusion groups, presumably far further back in the past before hominids became a distinct line, the development of the imaginary some 50,000 years ago enabled a huge explosion of cultural activity. A person who is dead is not dead, but has to be respected and prepared for an afterlife. These marks on the wall of a cave are not just marks, they are a bison. These stones are not just stones, but a necklace. Symbolism opens the door for more abstract, and thus fictional, narratives.

7. Myth, oral story-telling, religion, and ritual. The emergence of narrative together with the emergence of the imaginary in life prepared the mind for the convergence of conversation with play, as play began to take on verbal forms, and stories started to be not just (as in conversation) about what did happen, but about what might happen, or what could happen. Play is an activity that occurs in most mammals (PANKSEPP 1998), though it does not occur in reptiles. It is prominent in our cousins the apes as it no doubt was in our pre-symbolic ancestors. Among these beings it was presumably physical and included rough-and-tumble interactions of the kind that you can see in puppies or kittens. If we look at modern play in children, it is clear that it has easily assimilated the metaphorical, to become what developmental theorists call pretend play (LeSLIE 1987). One may hypothesize that with the emergence of the metaphorical, symbolic elements (e.g., props, dolls, roles, enactments) were also introduced. In verbal modes, stories would begin when talk included not just the usual conversational subjects of actual individuals and what they did, but possible individuals, symbolic individuals, and what they might do. Characters in such stories would start to include beings who had influence although they were no longer present, that is, supernatural beings.

Some of the early stories of this kind are called myth, usually defined as stories having to do with supernatural beings. Often, these are beings who were once alive but who are imagined to persist in a transformed state after death: the Mesopotamian kings became gods who must be obeyed, the Egyptian Pharaohs needed pyramids to house them when they were dead, Chinese ancestors had to be revered, Jesus was a man who rose from the dead and lives within the devout person, the //gangwasi ancestors (see LEE 1984) of the !Kung people of the Kalahari hover around and may make one ill if one does not behave properly. Myth is invariably told in narrative form. It invariably has a didactic aspect (cf. SCHANK and BERMAN 2002). It is partly about how to understand reality. Myths are what PETERSON (1999) has called "Maps of Meaning", or as RONALD WRIGHT (2004) has independently put it: 


\begin{abstract}
"Myth is an arrangement of the past, whether real or imagined, in patterns that reinforce a culture's deepest meanings and aspirations ... Myths are so fraught with meaning that we live and die by them. They are the maps by which cultures navigate through time." (p. 5)
\end{abstract}

Creation myths, the bases of religion, were also important products of these early narrative abilities. Stories were created to produce meaning and order in an unpredictable environment. The capacity for metaphor and symbolism enabled objects in the environment to be no longer simply themselves, but meaningfully to embody deities and spirits.

DonALD (1991) argues that mimesis was a fundamental preadaptation for the mythic. The non-verbal mode of mimesis joins with the verbal forms of myth, to produce religious ceremony and ritual, the importance of which is hard to overstate. It is a primary material from which culture is made. It concerns issues that are fundamental to us humans, the continuity of life and society, the meaning of what may otherwise seem accidental, the healing of the sick, the reintegration into society of those who have become alienated from it. Though DonALD proposes that myth emerged soon after language, it seems that with the almost invariable requirement of myth to imagine beings that are invisible, it is more likely to have emerged with metaphor, and was reflected in the ritual burying of the dead. Conversation, play, and imitation bind individuals to collective society and give life meaning; religion is a result of this binding.

It is hard to know when more secular stories would have arisen. Oral storytelling tends to have ritualistic elements, likely to aid the proper memorization and recitation of tales (HAvelock 1978). Probably it arose alongside the stories of myth and religion. One can imagine that as conversation occasionally became imaginative, it began to offer functional modes of thinking about people, their individuality, their concerns, and their emotions, outside of ideas of worship.

\title{
CHARACTER
}

If one reads accounts of the lives of chimpanzees by such researchers as GoodALL and DE WAAL, one recognizes that the world for these creatures has already ceased to be primarily a world of nature. While the life of chimpanzees does involve foraging, sleeping and a good deal of tree climbing, their world appears to have become more predominantly that of the immediate history of the social group. In human stories this trend away from raw nature towards the world of society and of technology (homes, tools, clothing, etc.) has continued further. The most critical aspect of human sociality is that each person is an individual whose history, relations, and characteristics become known to others. Even in a collectivist society, such individ- 
uality becomes the basis for interactions with this person. Whether stories are about individuals because of this feature of needing to know something about each individual in order to interact with him or her, or whether a focus on individuals and their doings has occurred in societies because we see the world through our stories, can perhaps not be known. In any event it has become inevitable that stories feature individuals. As BRUNER (1986) has put it: "[n]arrative is about the vicissitudes of human intentions" (p. 13).

Psychologically, character is a mental model of an actor in a story. It is abstracted from several sources such as how the person behaves, what the person says about him or herself, and what others say about that person. We also know of "character" as some judgement about a person's moral disposition in the real-world. With respect to this, Virginia Woolf remarked in a 1924 essay: we are all judges of character and we could not survive in the social world if we were not. Literary narrative adds a further layer: the interaction of characters with other characters and with events. It aims at a generalizable understanding people's goals (intentions), conflicts, and emotional life. It attempts to depict tendencies that are difficult to grasp but which, if understood, make sense of behavior. By contrast, the psychologists' idea of traits of personality is directed toward the narrower goal of assessing persistent behavioral tendencies based largely on self-report.

Character judgments in the real world are pervasive, immediate, and consistent. Empirically, one of the most intriguing studies on the acquired perception of character is by COIE and KUPERSMIDT (1983). They arranged 40-minute play sessions for ten-year-old boys, once a week for six weeks. The boys were put in groups of four; the children either knew each other previously because they were in the same class at school, or did not know each other because they were from different schools. Each four-boy group had one member who, from psychometric data from their originating school class, was popular and had been seen as a leader, one who had been seen as average, one who had been seen as aggressive and had been socially rejected, and one who had been seen as shy socially ignored. The boys in the groups who had previously known each other maintained their previous popularity and status in the four-boy play sessions. For those who had not previously known each other, by the end of their third session together, boys who had been popular at school had become popular in the play sessions, while those who had been rejected or unpopular at school had become rejected or unpopular in the play sessions. Reputation among these boys was thus formed very quickly, within two hours of interaction, and once formed a person's reputation in any group became difficult to change. In adults, OATLEY and LAROCQUE (1995) have found that after a mistake has occurred in a plan or arrangement WITH another person, individuals often jump eagerly to a judgment of character. If the person with whom the error occurred was not already well known and personally liked, a model of the person was quickly formed: "untrustworthy", 
"a flake", "a bitch". These models (read: character judgments) bias further interactions with individuals in ways congruent with the information they contain. In conversations, references to character also often reach towards people's goals. Thus, someone we describe as "not interested in people", can be expected to be overly devoted to his or her own work and perhaps somewhat socially awkward.

Literary character includes such elements, but the idea has been developed further towards abstraction and generalization. Although in Poetics, Aristotle proposed that plot was the most important element in tragedy, with the plays of Shakespeare, character overtook plot in importance. In fiction generally, this pre-eminent importance of character has been maintained subsequently so that as Henry JAMES (1884) could ask: "What is character but the determination of incident? What is incident but the illustration of character?" (p. 405)

Evolution has provided us with a set of pre-adaptations that include the ability to make mental models of others, the ability to transmute sequences of individual histories into conversational narratives, and the capacity for metaphor. Culture, and specifically writers within culture, have then worked up, as it were, a theory of character which gives our mental models far more depth, and far more generalizability, than can typically occur in a session of conversational gossip. The literary idea of character involves a number of developmental and cultural accomplishments (cf. OATLEY 2002), with some of the more recent cultural innovations having been accomplished by the writers of fiction, among whom Shakespeare is perhaps the most instructive.

Shakespeare's theory of character is thoroughly cognitive. He proposed that within a person there is a relation between inwardness (which he called substance) and outer behavior (which he often called shadow). The inward is an ensemble of goals and intentions orchestrated by one or more emotions that have been created, or have been affected by, life experiences. This substance, moreover, is a domain of inner reflection of a kind that Shakespeare famously accomplished in Hamlet (see GREENBLATT 2004), though such inwardness can perhaps never be fully known. The shadow (meaning in Shakespeare's time both what it means to us and also reflection, as in a mirror) is a set of distinctive outward actions that flow from the goals (intentions) and emotions of the substance, to accomplish particular projects in relation to particular others. Take for example the character of Cassius in Julius Caesar. In the play, Cassius tells Brutus that he had once been a friend of Caesar, and on one occasion had saved his life. At the beginning of the play Caesar, the greatest man in Rome, is described by Cassius as treating him now with disdain. In the action of the play this disdain is seen as inducing envy and shame in Cassius, which in turn generates anger (see SCHEFF 1997, for an account of how shame turns to rage) and the plot to assassinate Caesar. Essentially here we have the modern conception of character both in literary and everyday terms. It is an abstraction affected by experience, built of goals, intentions, and emotions, from which actions flow. 
Models of other people with whom we interact socially are first constructed through experience with these individuals. These representations of others are then transmitted and elaborated through the conversations that take place amongst peers. At a period in human history, stories about highly significant individuals - such as Julius Caesar - began to circulate widely and spread values important to the culture. Among the values promulgated by different characters of stories are bravery, heroism, humility, and piety. Some such stories gained the status of myth, which as McLuhAN (1964/1994) has said "is the instant vision of a complex process that ordinarily extends over a long period" (p. 25). Stories, and the characters that populate them can be, therefore, compressed representations of individual and group history.

Characters depicted in myths, however, were often described as mere conduits of actions, determinants of certain incidents. It needed authors such as Shakespeare to develop characters who were complex abstractions of possible individuals. Thus the fully developed protagonists of Shakespeare's plays were not mere cogs in a machinery of narrative causality. They contained essences of what real people are like. Modern literary characters are very complex representations. Early on in both cultural and individual development, writing tended to include characters who were determined largely by their context. By contrast, with the innovations introduced by Shakespeare, one can imagine (as suggested by BRADLEY 1904) Othello finding his way into Hamlet, and quickly taking command of the situation by virtue of his authority and decisiveness. He would have had the usurping Claudius arraigned in no time. In a comparable way Hamlet in Othello's play would quickly have seen through Iago, and in the next moment would be mimicking him. Simple stereotyped agents of action, or traits, are "flat" characters in the sense of FORSTER (1927), whereas more developed incarnations such as Othello can be considered, in Forster's terms, "round". Nineteenth-century writing introduced the further development of this idea, with creations such as Madame Bovary, Jane Eyre, Anna Karenina, and others. Some writers, such as Virginia Woolf and James JoYCE, demonstrated the potential of the narrative medium to depict the inner consciousness of another, and enabling the reader to enter yet more directly than previously into the mind (substance) of a fictional other, rather than just having the external behavior (shadow) depicted.

Understanding people, and understanding the characters in a piece of narrative fiction, probably involves similar processes. Empirically, RAPP and GERRIG (2001) have demonstrated that readers form trait-based character models of individuals when they read. They found some evidence that these models are rapidly updated as new information (e.g., model-incongruent action) is revealed. Others have found that a similar process of trait-model construction takes place in real-world character judgements (Park, Dekay and Kraus 1994). As in narratives, coherence is an 
important component of these character models (READ and MiLLER 1993; THAGARD and KUNDA 1998).

In literature currents that flow in conversation - of trust and distrust, of implications of actions and their generalizability to further actions, of aspirations to understand people's goals - are elaborated. But, unlike in conversation, in which we tend to treat a person in an immediate context of specific actions and emotional incidents, in literature a character is set in relation to universal abstractions and a generalized social milieu. A character can then, as it were, take off into cultural space and live a life of her or his own, as have Cinderella and Sherlock Holmes. We need something beyond conversation to have a chance of understanding the complexity of individuals in social worlds. This something is provided in literature, as simulations of the social world (OATLEY 1992).

Although, in literature, the specificity of literary characters is maintained, the understanding of human mentality and action that is depicted becomes more abstract. Because of this, an understanding can, perhaps, be applied more generally than an understanding derived from gossiping about an acquaintance.

How is this abstraction and generalization achieved? First, with some literary characters we can experience an ironic distance that allows us simultaneously both subjective experience and external observation. This is an effect accomplished as explained by Luввоск (1921) with respect to Flaubert's Madame Bovary. In the novel, we see Emma Bovary's world through her eyes as she becomes in turn weary, resigned, or ecstatic. At the same time we see her actions and her objects of thought through the eyes of the author Flaubert as vulgar and sentimental. Our consciousness of a story-protagonist thus goes beyond the kind of knowledge we can easily have of ourselves or of other people. Sometimes, in Flaubert's novel, we encompass both the subjective and the objective (or at least, external) simultaneously. Among our sources of information and evaluation here are (a) the character's subjective experience, (b) the author's evaluations of this character, and (c) our own subjective evaluations of this character evoked by the narrative experience. Surprisingly, then, we can come to know a fictional character better than someone in real life, better perhaps in some respects than ourselves. This kind of knowledge also generalizes beyond knowledge of any specific character. The insight afforded by a window into a character's "inwardness" provides one with an evocative framework from which inferences beyond the text may be developed. This possibility is based upon a departure from the creation of characters who are determined solely by their material environment (WoOLF 1924).

A reader may identify with a character, as he or she mentally runs the simulation of a novel or play. In so doing the reader may come to like, and then to become somewhat like, the character. The psychological effects of character, then, include the pleasing surprise of recognition, the satisfaction of being able to understand 
visible behavior in terms of deeper principles, the insight of seeing both others and ourselves in terms of human attributes that are both valued and problematic. But self and others are not necessarily seen in the same ways. CUPCHIK and HILSCHER (2005) have shown categorization of one's own self in one kind of way, of other selves in different ways, with yet further categories for belongingness to one's community.

In experiments with short stories by MUNRO and BIERCE, KERR (2005) has found that identification with a main character increases literary involvement, as measured by the number of emotions readers experienced while reading the stories. The degree of involvement was correlated significantly with increased insight. Along similar lines, GREEN (2004) has demonstrated that knowledge or familiarity with the situation of a protagonist results in greater transportation into a narrative world, and that this engagement further predicts the endorsement of story-consistent beliefs. Literature, therefore, is a means through which we can get to understand ourselves and others better. The impact of character in novels is that, as the reader enters, Alice-like, through the looking glass of narrative, he or she can enter other minds that are in some ways like his or her own, and in some ways unlike. The impact of this experience illuminates the nature of selfhood. Because this experience of being within another mind is accompanied by other impressions also, such as the character being seen by others, it offers the reader the possibility of not just the clarification of his or her mental models of self, but also of their transformation.

Our capacity for comprehending and even producing complex literary characters is likely something which evolved gradually much as language and metaphoric thought. In individuals, developmentally, this at least appears to be the case. Thus McKeough and Generux (2003) have found evidence for a gradual progress in abstraction of character in the written stories of adolescents. Participants from various age groups (on average 10,12,14 and 17 years) were asked to write a story about a character who has a problem, and to include at least one flashback in the story. The researchers found that rather than intentional or physical descriptions, older children tended to include more interpretive descriptions of characters of a kind that would generalize beyond immediate motivations. An increase was even observed between the two oldest groups of children, demonstrating that this sort of knowledge continues to grow during late adolescence. This same study also found that older children tend to produce narratives that are more complex along various dimensions (e.g., plot structure).

\section{CONCLUSION}

Literary art is by definition written, and writing is a product of culture rather than evolution. Nonetheless, we propose, the carefully crafted story that one reads as a novel, or sees as a play or movie, is based on an elaborate series of evolutionary pre- 
adaptations each one of which takes us closer to the literate story-telling cultures with which we are familiar today. Story characters the products of, and the shapers of, social understanding, representing a continual honing of our comprehension of our social world.

Human beings are social creatures. We are also the creatures that make things, including art. We are the creatures who make meaning of our social worlds. One could argue that such preoccupations are dodo-like dead-ends. Or one could argue that these are features that make our species distinctive, in the same way that the black and white stripes of a zebra are distinctive.

\section{REFERENCES}

Aiello, L. C. and Dunbar, R. I. M. (1993): Neocortex size, group size, and the evolution of language. Current Anthropology, 34, 184-193.

Aristotle. (c. 330 BCE): Poetics (G. E. Else, Trans.). Ann Arbor, MI: University of Michigan Press (1970).

Barrett, L., Henzi, P. and Dunbar, R. I. M. (2003): Primate cognition: From "what now?" to "what if?" Trends in Cognitive Sciences, 7, 494-497.

Bradley, A. C. (1904): Shakespearian Tragedy. London: Macmillan.

Bruner, J. (1986): Actual Minds, Possible Worlds. Cambridge: Harvard University Press.

COIE, J. D. and KUPERSMIDT, J. D. (1983): A behavioral analysis of emerging social status in boys' groups. Child Development, 54, 1400-1416.

Cosmides, L. and ToOBY, J. (1994): Beyond intuition and instinct blindness. Towards an evolutionarily rigorous cognitive science. Cognition, 50, 41-77.

CUPCHIK, G. C. and HILSHER, M. C. (2005 in press): The roots of life-narrative in personal and evolutionary contexts. Journal of Cultural and Evolutionary Psychology.

DE WAAL, F. (1982): Chimpanzee Politics. New York: Harper and Row.

Donald, M. (1991): Origins of the Modern Mind. Cambridge, MA: Harvard University Press.

Dunbar, R. I. M. (1993): Coevolution of neocortical size, group size and language in humans. Behavioral and Brain Sciences, 16, 681-735.

DunBar, R. I. M. (1996): Grooming, Gossip and the Evolution of Language. London: Faber and Faber.

DunBar, R. I. M. (2004). The Human Story: A New History of Mankind's Evolution. London: Faber.

Fillmore, C. J. (1968): The case for case. In E. Bach and R. T. Harms (eds): Universals in Linguistic Theory. New York: Holt, Rinehart and Winston, 1-88.

FORSTER, E. M. (1927): Aspects of the Novel. London: Edward Arnold.

Gallese, V., Ferrari P., Kohler, E. and Fogassi, L. (2002): The eyes, the hand, and the mind: Behavioral and neurophysiological aspects of social cognition. In M. Bekoff, C. Allen, and G. M. Burghardt (eds): The Cognitive Animal: Empirical and Theoretical Perspectives on Animal Cognition. Cambridge, MA: MIT Press, 451-461.

Gallese, V., Keysers, C. and Rizzolati, G. (2004): A unifying view of the basis of social cognition. Trends in Cognitive Sciences, 8, 396-403.

GreEN, M. C. (2004): Transportation into narrative worlds: The role of prior knowledge and perceived realism. Discourse Processes, 38, 247-266. 
Greenblatt, S. (2004): Will in the World: How Shakespeare Became Shakespeare. New York: Norton.

Goodall, J. (1986): The Chimpanzees of Gombe: Patterns of Behavior. Cambridge, MA: Harvard University Press.

Halliwell, S. (2002): The Aesthetics of Mimesis: Ancient Texts and Modern Problems. Princeton, NJ: Princeton University Press.

Havelock, E. A. (1978): The Greek Concept of Justice: From its Shadow in Homer to its Substance in Plato. Cambridge: Harvard University Press.

Iacoboni, M., Woods, R. P., Brass, M., Bekkering, H., Mazziotta, J. C. and Rizzolatti, G. (1999): Cortical mechanisms of human imitation. Science, 286, 2526-2528.

KERR, A. (2005). Towards a Therapeutics of Reading Literature: The Influence of Aesthetic Distance and Attachment. Unpublished PhD, University of Toronto.

JAMES, H. (1884): The art of fiction. Longman's Magazine, September. Reprinted in M. D. Zabel (ed.): The Portable Henry James. (1951) New York: Viking, 391-418.

LAmarcque, P. (2003): Fiction. In J. Levinson (ed.): The Oxford Handbook of Aesthetics. Oxford: Oxford University Press, 392-407.

LEE, R. B. (1984): The Dobe !Kung. New York: Holt, Rinehart and Winston.

Leslie, A. M. (1987): Pretence and representation: the origins of "theory of mind". Psychological Review, 94, 412-426.

LubBock, P. (1921): The Craft of Fiction. London: Cape.

MAR, R. A. (2004): The neuropsychology of narrative: Story comprehension, story production and their interrelation. Neuropsychologia, 42, 1414-1434.

McKeough, A. and Genereux (2003): Transformation in narrative thought during adolescence: The structure and content of story compositions. Journal of Educational Psychology, 95, 537-552.

McLuHan, M. (1964/1994): Understanding Media: The Extensions of Man. Cambridge, MA: MIT Press.

Mithen, S. (1996): The Prehistory of the Mind: The Cognitive Origins of Art and Science. London: Thames and Hudson.

Mithen, S. (2001): The evolution of imagination: An archeological perspective. SubStance, 94/95, 28-54.

OAtley, K. (1992): Best Laid Schemes: The Psychology of Emotions. Cambridge: Cambridge University Press.

OAtLEy, K. (2002): Emotions and the story worlds of fiction. In M. C. Green, J. J. Strange and T. C. Brock (eds): Narrative Impact: Social and Cognitive Foundations. Mahwah, NJ: Erlbaum, 39-69.

OATLEY, K. (2003): Creative expression and communication of emotion in the visual and narrative arts. In R. J. Davidson, K. R. Scherer and H. H. Goldsmith (eds): Handbook of Affective Sciences. New York: Oxford University Press, 481-502.

OATLEY, K. and LAROCQUE, L. (1995): Everyday concepts of emotions following every-other-day errors in joint plans. In J. Russell, J.-M. Fernandez-Dols, A. S. R. Manstead and J. Wellenkamp (eds): Everyday Conceptions of Emotions: An Introduction to the Psychology, Anthropology, and Linguistics of Emotion. NATO ASI Series D 81. Dordrecht: Kluwer, 145-165.

PANKSEPP, J. (1998): Affective Neuroscience: The Foundations of Human and Animal Emotions. Oxford: Oxford University Press.

Park, B., DeKay, M. L. and Kraus, S. (1994): Aggregating social behavior into person models: Perceiver-induced consistency. Journal of Personality and Social Psychology, 66, 437-459.

Peterson, J. (1999): Maps of Meaning: The Architecture of Belief. London: Routledge. 
Power, R. (1979): The organization of purposeful dialogues. Linguistics, 17, 107-152.

RAPP, D. N. and GERRIG, R. J. (2001): Readers' trait-based models of characters in narrative comprehension. Journal of Memory and Language, 45, 737-750.

ReAD, S. J. and Miller, L. C. (1993): Rapist or "regular guy": Explanatory coherence in the construction of mental models of others. Personality and Social Psychology Bulletin, 19, 526-541.

Rizzolatti G. and ARBiB, M. A. (1998): Language within our grasp. Trends in Neuroscience, 21, 188-194.

Schank, R. C. and Berman, T. R. (2002): The pervasive role of stories. In M. C. Green and J. J. Strange and T. C. Brock (eds): Narrative Impact: Social and Cognitive Foundations. Mahwah, NJ: Erlbaum, 287-313.

SCHEFF, T. J. (1997): Emotions, the Social Bond, and Human Reality: Part/whole Analysis. New York: Cambridge University Press.

Thagard, P. and Kunda, Z. (1998): Making sense of people: Coherence mechanisms. In S. J. Read and L. C. Miller (eds): Connectionist Models of Social Reasoning and Social Behaviour. Mahwah, NJ: Erlbaum, 3-26.

Tooby, J. and Cosmides, L. (2001): Does beauty build adapted minds? Towards an evolutionary theory of aesthetics, fiction and the arts. SubStance, 94/95, 6-27.

Tomasello, M. (1999): The Cultural Origins of Human Cognition. Cambridge, MA: Harvard University Press.

Woolf, V. (1924): Mr Bennett and Mrs Brown. In Collected Essays. Vol 1. London: Hogarth Press, 319-337 (current edition, 1966).

Wright, R. (2004). A Short History of Progress. Toronto: Anansi. 